\title{
Antidiabetic and Hypolipidemic Activities of Curculigo latifolia Fruit:Root Extract in High Fat Fed Diet and Low Dose STZ Induced Diabetic Rats
}

\author{
Nur Akmal Ishak, ${ }^{1}$ Maznah Ismail, ${ }^{1,2}$ Muhajir Hamid, ${ }^{3}$ Zalinah Ahmad, \\ and Siti Aisyah Abd Ghafar ${ }^{1}$ \\ ${ }^{1}$ Nutricosmeceutical and Nutrigenomic Programme, Laboratory of Molecular Biomedicine, \\ Institute of Bioscience, Universiti Putra Malaysia, 43400 UPM Serdang, Selangor Darul Ehsan, Malaysia \\ ${ }^{2}$ Department of Nutrition and Dietetics, Faculty of Medicine and Health Sciences, Universiti Putra Malaysia, \\ 43400 UPM Serdang, Selangor Darul Ehsan, Malaysia \\ ${ }^{3}$ Department of Microbiology, Faculty of Biotechnology and Biomolecular Sciences, Universiti Putra Malaysia, \\ 43400 UPM Serdang, Selangor Darul Ehsan, Malaysia \\ ${ }^{4}$ Chemical Pathology Unit, Department of Pathology, Faculty of Medicine and Health Sciences, \\ Universiti Putra Malaysia, 43400 UPM Serdang, Selangor Darul Ehsan, Malaysia
}

Correspondence should be addressed to Maznah Ismail; maznah@medic.upm.edu.my

Received 1 February 2013; Revised 4 April 2013; Accepted 4 April 2013

Academic Editor: Mohamed Eddouks

Copyright (C) 2013 Nur Akmal Ishak et al. This is an open access article distributed under the Creative Commons Attribution License, which permits unrestricted use, distribution, and reproduction in any medium, provided the original work is properly cited.

Curculigo latifolia fruit is used as alternative sweetener while root is used as alternative treatment for diuretic and urinary problems. The antidiabetic and hypolipidemic activities of C. latifolia fruit:root aqueous extract in high fat diet (HFD) and $40 \mathrm{mg}$ streptozotocin (STZ) induced diabetic rats through expression of genes involved in glucose and lipid metabolisms were investigated. Diabetic rats were treated with $C$. latifolia fruit:root extract for 4 weeks. Plasma glucose, insulin, adiponectin, lipid profiles, alanine aminotransferase (ALT), gamma glutamyltransferase (GGT), urea, and creatinine levels were measured before and after treatments. Regulations of selected genes involved in glucose and lipid metabolisms were determined. Results showed the significant $(P<0.05)$ increase in body weight, high density lipoprotein (HDL), insulin, and adiponectin levels and decreased glucose, total cholesterol (TC), triglycerides (TG), low density lipoprotein (LDL), urea, creatinine, ALT, and GGT levels in diabetic rats after 4 weeks treatment. Furthermore, C. latifolia fruit:root extract significantly increased the expression of IRS-1, IGF-1, GLUT4, PPAR $\alpha, P P A R \gamma$, AdipoR1, AdipoR2, leptin, LPL, and lipase genes in adipose and muscle tissues in diabetic rats. These results suggest that $C$. latifolia fruit:root extract exerts antidiabetic and hypolipidemic effects through altering regulation genes in glucose and lipid metabolisms in diabetic rats.

\section{Introduction}

Type 2 diabetes mellitus is a metabolic disorder which causes hyperglycemia [1] due to defect in insulin secretion and insulin resistance [2]. It results from failure of pancreatic $\beta$-cell to secrete insulin sufficiently in response to elevate blood glucose [3]. In early stage of type 2 diabetes mellitus, peripheral tissues such as liver, muscle, and adipose tissues are not sensitive towards insulin [4] and they cause common symptoms such as increased thirsty, frequent urinary, ketonuria and ketonemia in diabetic patients [5]. In a longterm of insulin resistance period, it will lead to chronic hyperglycemia and hyperlipidemia in diabetic patients [6]. Therefore, if no prevention action is taken, diabetes can lead 
to several complications such as heart attack, nephropathy, retinopathy, and neuropathy [7].

Till now, numerous types of diabetic models are used for screening antidiabetic properties of plants. These diabetic models are developed through several methods either through genetic or chemically induced diabete [8]. There are genetic models of diabetes known as $\mathrm{db} / \mathrm{db}$ mouse and Zucker diabetic fatty (ZDF) rats which develop similar features as in human type 2 diabetes [9]. However, the development of diabetes in these rats is due to genetic and this is unlikely in humans. Besides, these rats are expensive to be used as diabetic models for pharmacological screening [10]. Meanwhile, development of diabetic rats following streptozotocin (STZ) injection also presents hyperglycemia similar to human type 2 diabetes mellitus [11]. However, this method only develops insulin deficiency rather than insulin resistance in the model [12]. Despite that, the pattern of disease progress did not appear to be similar to diabetic situation in human type 2 diabetes mellitus. Thus, several researchers have been investigating to find a better diabetic model for type 2 diabetes mellitus by modifying the existing method. Recently, many studies reported that rats induced with high fat diet with combination of (STZ) have developed similar situation as type 2 diabetes progress in humans. Diets containing high fat will cause insulin resistance in peripheral tissues due to lipotoxicity [13]. Meanwhile, low dose of STZ has known to induce mild defect in insulin secretion, which is similar to the characteristics of the later stage of type 2 diabetes [14]. Combination of high fat diet with low dose STZ has successfully mimicked natural progress of diabetes development as well as metabolic features in human type 2 diabetes $[15,16]$. Apart from that, these models are also cheaper, easy to develop, and practical for pharmacological screening [17].

Currently, there are five major classes of therapeutic drugs that have been used to treat diabetes through several target sides: sulfonylureas, biguanides, thiazolidinediones, meglitinide, and $\alpha$-glucosidase inhibitor. However, according to Bastaki (2005), combination of two drugs such as metformin and sulfonylurea can increase the hypoglycemic activity where it treats diabetes through two different modes of action [18]. In spite of antidiabetic drugs effectiveness, prolonged usage of it will cause adverse effect. Sulfonylureas have been reported to cause hypoglycemia, increase in body weight, gastrointestinal (GI) disturbance, and headache to the user [19]. Besides, metformin could cause abdominal pain, diarrhea, nausea, and lactic acidosis to the diabetic patient [20]. In other diabetic drug that causes adverse side effects is thiazolidinediones as it causes hepatotoxicity after long-time usage [21]. Apart from adverse side effect, antidiabetic drug also has limited mode of action. Available diabetic drugs only show single mode of action in treating diabetes and then need to combine with another class of antidiabetic drug to make these drugs more efficient such as combination of metformin and sulfonylurea [18].

Although there was a plenty amount of antidiabetic drugs available, the numbers of type 2 diabetes mellitus patients are still increased constantly. The incidence of T2DM has become worldwide epidemic and there are approximately 246 million people who are suffering from this disease [22]. The highest rate of diabetic population is in India with current figure 40.9 million and followed by China with 39.8 million. Furthermore, Pakistan, Japan, USA, Russia, and Germany are also widely affected with diabetes [22]. This number is continually increasing and it might be due to antidiabetic drug adverse side effect and also due to drug limitation action.

There is a dramatic revival of interest in using natural sources in treating diabetes due to side effects of prolonged consumption of therapeutic drugs. Asian countries such as India and China are already known for their contributions toward the usage of plant medicine in preventing and overcoming diabetes problems [23, 24]. More than 4000 plants have been studied and identified to have hypoglycemic effect through several mechanisms of antidiabetic activity. Some plants acts through either secretagogues or insulin mimetic properties such as Momordica charantia, Aloe vera, and Allium sativum [25-27]. Studies have reported that these plants have the ability to reduce blood glucose and improve insulin secretion [28]. Meanwhile, according to Malviya et al. (2010), secondary metabolites from plants such as phenolic, alkaloids, and glycosides are the ones which are implicated as having antidiabetic effect [26]. Among those secondary metabolites, phenolic compounds are the ones which are abundantly present in plants and are demonstrated to have antioxidant, antidiabetic, and antiobesitiy properties [29].

Curculigo latifolia (Dryand, ex W. T.Aiton) is a shrub tree that mainly grows under rubber tree and it is also known as Lemba among local community in Malaysia [30]. This plant belongs to the Hypoxidaceae family. To date, there are about 20 species of Curculigo that have been identified and C. latifolia and C. capitulate are mostly distributed in Malaysia [31]. This shrub tree consists of berry-like fruit and this fruit exhibits both sweet tasting and taste modifying activities [32]. Curculin and neoculin have been identified as proteins that possess those activities [33]. Despite $C$. latifolia is sweet and can be used as alternative sweetener for diabetic patient, and there is no scientific study on $C$. latifolia as antidiabetic agent. Preliminary study that has been conducted in our laboratory showed that C. latifolia fruit and root extracts have the highest antioxidant activity where the $\mathrm{IC}_{50}$ for both of the fruit and root extracts is $1.0 \mathrm{mg} / \mathrm{mL}$. In spite of high antioxidant, fruit and root also consist of high phenolic content, $95 \mathrm{mg}$ GAE/100 g extract and $90 \mathrm{mg} \mathrm{GAE} / 100 \mathrm{~g}$ extract. Both data revealed that there is positive correlation between total phenolic content and antioxidant activity in fruit and root. Besides, an in vitro study that has been conducted in our laboratory indicates that $C$. latifolia fruit and root extracts have antidiabetic activity by increased insulin and adiponectin secretion in cell lines. $C$. latifolia fruit and root extracts also significantly increased glucose uptake activity in 3T3 adipocytes and L6 myotubes cell lines (patent pending). The present study was performed to determine antidiabetic and hypolipidemic activities of $C$. latifolia fruit:root extract in HFD and low dose STZ induced diabetic rats by evaluating the potential of this plant to regulate expression of genes involved in glucose and lipid metabolisms. 
TABLE 1: Nutrient composition of NPD and HFD.

\begin{tabular}{lcc}
\hline Nutrient & \% in $100 \mathrm{~g}$ of NPD & \% in $100 \mathrm{~g}$ of HFD \\
\hline Fat & 4 & 34 \\
Fiber & 5 & 3 \\
Protein & 14 & 16 \\
Carbohydrate & 72 & 42 \\
Mineral and vitamin mix & 5 & 5 \\
\hline Total calories $(\mathrm{kcal} / 100 \mathrm{~g})$ & 380 & 538 \\
\hline
\end{tabular}

\section{Materials and Methods}

2.1. Preparation of C. Latifolia fruit:root Extract. C. latifolia plant was collected from Beranang, Selangor, Malaysia. It was identified by the taxonomist from the Biodiversity Unit in the Institute of Bioscience, Universiti Putra Malaysia with voucher number SK 1709/09. The fruits were plucked at the apex of $C$. latifolia stem, cleaned with tap water, blotted with tissue paper, and stored at $-20^{\circ} \mathrm{C}$ until further use. Roots were cleaned with tap water and immediately dried for overnight in an air oven (Memmert, Schwabach, Germany) at $40^{\circ} \mathrm{C}$. Dried roots were grounded to fine powder using electric grinder (Philips, Malaysia). Powdered root was sealed in plastic bags and kept at $4^{\circ} \mathrm{C}$ until further use.

2.1.1. Extraction of C. Latifolia Fruits:Root. Fifty grams of fresh $C$. latifolia fruits was mashed using mortar and pestle. Mashed fruits were extracted with $2000 \mathrm{~mL}$ of distilled water. Meanwhile, $50 \mathrm{~g}$ of $C$. latifolia root powder was soaked in $2000 \mathrm{~mL}$ of distilled water. Both extractions were extracted $24 \mathrm{~h}$ with continuous stirring at room temperature. This extract was filtered through Whatman number 1 filter paper and the filtrate was collected and lyophilized. The lyophilized sample was kept at $-80^{\circ} \mathrm{C}$ until further use. In this study, fruit and root extracts were mixed at 1:1 ratio for rats treatment.

2.2. Preparation of High Fat Diet (HFD). The normal pallet diet from Miba Mansura (Malaysia) consists of $46 \%$ of cornstarch, $26 \%$ of palm kernel meal, $4 \%$ of soybean oil, $3.5 \%$ of minerals mixture, $1 \%$ of vitamins mixture, $0.25 \%$ of choline bitartrate, and $0.18 \%$ of L-cystine. The nutrient composition is shown as Table 1 . The HF diet was formulated based on the composition provided by Levin et al. (1989) [34]. It will be prepared from a mixture of $50 \%$ normal rat chow pellet, $24 \%$ of corn oil (Mazola brand), $20 \%$ of full-cream milk powder (NESPRAY brand from Nestlé), and 6\% sugar.

2.3. Animal Study. Forty-two male Sprague-Dawley rats weighing 160-180 g each were housed individually in polypropylene cages and maintained under controlled room temperature $\left(22 \pm 2^{\circ} \mathrm{C}\right)$ and humidity $(55 \pm 5 \%)$ with 12:12 h light-dark cycle. All experimental protocols for animal care and use were approved by the Animal Care and Use Committee (ACUC) of the Faculty of Medicine and Health Sciences, Universiti Putra Malaysia (project approval number UPM/FPSK/PADS/BR-UUH/0030). Upon receipt, rats were acclimatized for a week with free access of water and normal pellet diet. After acclimatized, normal rats $(n=6)$ were maintained on normal pellet diet while remaining rats were given high fat diet to induce obesity. This treatment was conducted for 4 weeks. After 4 weeks, obese rats were anesthetized with diethyl ether after being fasted overnight and injected with $40 \mathrm{mg} / \mathrm{kg}$ bw of STZ via intravenous to induce type 2 diabetes. Diabetic rats (fasting blood glucose level $>170 \mathrm{mg} / \mathrm{dL}$ after 7 days of STZ injected) were randomly divided into 5 groups (Groups 3, 4, 5, 6, and 7) and each group consists of 6 rats. Below are the lists of the rat groups for this study.

Group 1: normal (normal pellet diet, untreated) rats. Group 2: obese (high fat-fed diet, obese, untreated) rats.

Group 3: diabetic control (high fat-fed diet, induced with STZ, diabetic, untreated) rats.

Group 4: diabetic test rats (high fat-fed diet, induced with STZ, diabetic) treated with $50 \mathrm{mg} / \mathrm{kg}$ bw of $C$. latifolia fruit:root extracts.

Group 5: diabetic test rats (high fat-fed diet, induced with STZ, diabetic), treated with $100 \mathrm{mg} / \mathrm{kg}$ bw of $C$. latifolia fruit:root extracts.

Group 6: diabetic test rats (high fat-fed diet, induced with STZ, diabetic), treated with $200 \mathrm{mg} / \mathrm{kg}$ bw of $C$. latifolia fruit:root extracts.

Group 7: diabetes test rats (high fat-fed diet, induced with STZ, diabetic) treated with $10 \mathrm{mg} / \mathrm{kg} \mathrm{bw}$ of glibenclamide.

Treatment on diabetic rats was done for 4 weeks. Body weight of each rat was recorded before ( 0 week) and after 4 weeks of treatment. At the end of the experimental period, all rats were fasted for $15 \mathrm{~h}$ prior to sacrifice. Blood samples were collected by cardiac puncture. Meanwhile, adipose and muscle tissues were excised and stored at $-80^{\circ} \mathrm{C}$ prior used.

2.4. Biochemical Parameter Analysis of Blood. Blood samples were collected using $\mathrm{K}_{2}$ EDTA blood collection tube (BD Diagnostics, Franklin Lakes, NJ, USA). Plasma was collected after blood was centrifuged at $3000 \mathrm{rpm}$ for 10 minutes [35]. Biological assay such as glucose, total cholesterol (TC), triglycerides (TG), low density lipoprotein (LDL), high density lipoprotein (HDL), urea, creatinine, alanine aminotransferase (ALT), and $\gamma$-glutamyltransferase (GGT) was measured using Selectra XL clinical chemistry analyzer (Vital Scientific, the Netherlands). Insulin level was measured using rat insulin ELISA kit (Mercodia AB, Uppsala, Sweeden) with rat insulin as a standard. Adiponectin level was measured using BioVision rat adiponectin ELISA assay (BioVision Inc., Mountain View Milpitas, CA, USA).

\subsection{Quantification of Different Expression Genes between} Group Treatments Using GenomeLab. The white adipose tissues (retroperitoneal, subcutaneous, and epididymal) and muscle tissues were harvested from rats. Frozen tissues were thawed and homogenized and total RNA was extracted 
TABLE 2: Sequence of primers used.

\begin{tabular}{|c|c|c|}
\hline $\begin{array}{l}\text { Accession } \\
\text { number }\end{array}$ & Left sequence w/universals & Right sequence w/universals \\
\hline $\begin{array}{l}\text { NM_012969 } \\
\text { (IRS1) }\end{array}$ & $\begin{array}{l}\text { AGGTGACACTATAGAATAACCCT } \\
\text { AGACCCACTGCCTTT }\end{array}$ & $\begin{array}{l}\text { GTACGACTCACTATAGGGATGGAGGAAGCA } \\
\text { AGCAGAAAT }\end{array}$ \\
\hline $\begin{array}{l}\text { NM_013124 } \\
(\operatorname{PPAR} \gamma)\end{array}$ & $\begin{array}{l}\text { AGGTGACACTATAGAATAGATCCTCCTG } \\
\text { TTGACCCAGA }\end{array}$ & $\begin{array}{l}\text { GTACGACTCACTATAGGGATCAAAGGAATGGG } \\
\text { AGTGGTC }\end{array}$ \\
\hline $\begin{array}{l}\text { NM_178866 } \\
\text { (IGF) }\end{array}$ & $\begin{array}{l}\text { AGGTGACACTATAGAATACCGCTGAAGCC } \\
\text { TACAAAGTC }\end{array}$ & $\begin{array}{l}\text { GTACGACTCACTATAGGGAGCTCAAGCAGCAA } \\
\text { AGGATCT }\end{array}$ \\
\hline $\begin{array}{l}\text { NM_012751 } \\
\text { (GLUT4) }\end{array}$ & $\begin{array}{l}\text { AGGTGACACTATAGAATAAATGACTGAGGGG } \\
\text { CAAAATG }\end{array}$ & $\begin{array}{l}\text { GTACGACTCACTATAGGGAGGGTAAGAGGAA } \\
\text { GGCAGGAC }\end{array}$ \\
\hline $\begin{array}{l}\text { NM_207587 } \\
\text { (AdipoR1) }\end{array}$ & $\begin{array}{l}\text { AGGTGACACTATAGAATAGGACTTGGCTTG } \\
\text { AGTGGTGT }\end{array}$ & $\begin{array}{l}\text { GTACGACTCACTATAGGGACGGAATTCCTGTA } \\
\text { GGTTGGA }\end{array}$ \\
\hline $\operatorname{Kan}^{r}$ & $\begin{array}{l}\text { AGGTGACACTATAGAATAATCATCAGCA } \\
\text { TTGCATTCGATTCCTGTTTG }\end{array}$ & $\begin{array}{l}\text { GTACGACTCACTATAGGGAATTCCGACTCGT } \\
\text { CCAACATC }\end{array}$ \\
\hline $\begin{array}{l}\text { NM_013196 } \\
(\operatorname{PPAR} \alpha)\end{array}$ & $\begin{array}{l}\text { AGGTGACACTATAGAATACTCGTGCAGGTCA } \\
\text { TCAAGAA }\end{array}$ & $\begin{array}{l}\text { GTACGACTCACTATAGGGAGCCTCTGATCACC } \\
\text { ACCATTT }\end{array}$ \\
\hline $\begin{array}{l}\text { NM_013076 } \\
\text { (Leptin) }\end{array}$ & $\begin{array}{l}\text { AGGTGACACTATAGAATACAAAACGTGC } \\
\text { TGCAGATAGC }\end{array}$ & $\begin{array}{l}\text { GTACGACTCACTATAGGGACATTCAGGGCTA } \\
\text { AGGTCCAA }\end{array}$ \\
\hline $\begin{array}{l}\text { NM_012598 } \\
\text { (LPL) }\end{array}$ & $\begin{array}{l}\text { AGGTGACACTATAGAATAACTCGCTCTCA } \\
\text { GATGCCCTA }\end{array}$ & $\begin{array}{l}\text { GTACGACTCACTATAGGGACTGACCAGCGGA } \\
\text { AGTAGGAG }\end{array}$ \\
\hline $\begin{array}{l}\text { NM_012859 } \\
\text { (Lipase) }\end{array}$ & $\begin{array}{l}\text { AGGTGACACTATAGAATACCTTCGGGGAA } \\
\text { CACTACAAA }\end{array}$ & $\begin{array}{l}\text { GTACGACTCACTATAGGGACCAAGGGAGGTG } \\
\text { AGATGGTA }\end{array}$ \\
\hline $\begin{array}{l}\text { NM_023964 } \\
\text { (GAPDH) }\end{array}$ & $\begin{array}{l}\text { AGGTGACACTATAGAATAATCAATGGATTT } \\
\text { GGACGCAT }\end{array}$ & $\begin{array}{l}\text { GTACGACTCACTATAGGGAAGCTCCAGGGGA } \\
\text { TTTCCTTA }\end{array}$ \\
\hline BC168964 & $\begin{array}{l}\text { AGGTGACACTATAGAATACGGAAGAAGGCT } \\
\text { CTTGAAAA }\end{array}$ & $\begin{array}{l}\text { GTACGACTCACTATAGGGACGCCACCCTCTT } \\
\text { CATCTCTA }\end{array}$ \\
\hline $\begin{array}{l}\text { NM_001037979 } \\
\text { (AdipoR2) }\end{array}$ & $\begin{array}{l}\text { AGGTGACACTATAGAATACGGTGTACTGCCA } \\
\text { CTCAGAA }\end{array}$ & $\begin{array}{l}\text { GTACGACTCACTATAGGGAGCAAGGTAGGGAT } \\
\text { GATTCCA }\end{array}$ \\
\hline
\end{tabular}

using RiboPure isolation of high quality total RNA (Ambion, USA) according to manufacturer's instructions. Reverse transcription and PCR procedures were performed according to GenomLab GeXP kit protocol (Beckman Coulter, USA) using XP Thermal Cycler (Bioer Technology, Germany). The amplicons from PCR reaction were used for quantification of different expression genes between group treatments using GenomeLab GeXP Start kit. Samples were prepared and were added to the appropriate wells of 96-well sample microplate. All the samples were run in triplicates. Besides, all the data were analyzed using Express analysis software where fragment data is easily identified. Multiplex genes were normalized with $18 \mathrm{~S}$ by dividing the peak area of each gene by peak area of $18 \mathrm{~S}$ gene. The expression level was calculated according to the following formula:

Fold change

$$
\frac{\text { Normalized data of the gene from treated samples }}{\text { Normalized data of the gene from untreated samples }} \text {. }
$$

Primer sequences for all rat genes were designed using eXpress designer module of the GenomeLab eXpress Profiler software based on gene sequences from GeneBank database (Table 2).
2.6. Statistical Analyses. All results are expressed as the mean \pm standard deviation. The data were analyzed using one-way analysis of variance (ANOVA), followed by Tukey's post hoc test. Level of significance was set at $P<0.05$.

\section{Results}

3.1. Energy Contributed from HFD. In the present study, diabetic rats were developed using high fat diet. The high fat diet was formulated according to Levin et al's [34] method. The nutrient composition of NPD and HFD used in this experiment was mentioned in Table 1. Meanwhile, Table 3 shows the energy contributed from NPD and HFD. Energy contributed from fat sources in HFD diet was $56.9 \%$ and it indicates that there was $47.4 \%$ increase in fat composition in HFD compared to NPD. In spite of fat, energy contributed by protein and carbohydrate was $11.9 \%$ and $31.2 \%$.

3.2. Body Weight. Body weight from week 0 to week 4 of normal, obese, untreated diabetic and treated diabetic rats increased significantly $(P<0.05)$. In normal rats (Group 1 ), body weight increased by $20 \%$ followed by $30 \%$ in obese rats (Group 2). Meanwhile, body weight of diabetic control rats (Group 3) increased by 6\%. However, body weight of diabeticrats treated with $C$. latifolia fruit:root extract increased by 12\% (Group 4), 9\% (Group 5), and 7\% (Group 6) after 4 weeks of treatment. Body weight of diabetic rats in 
TABLE 3: Energy contributed from NPD and HFD.

\begin{tabular}{lcccc}
\hline Nutrient & \% in 100 g of NPD & \% energy in NPD & \% in 100 g of HFD & \% energy in HFD \\
\hline Fat & 4 & 9.5 & 34 & 56.9 \\
Protein & 14 & 14.7 & 16 & 11.9 \\
Carbohydrate & 72 & 75.8 & 42 & 31.2 \\
\hline
\end{tabular}

Percentage (\%) of energy was measured by kilocalories.

TABLE 4: The plasma glucose level and percentage of plasma glucose changes.

\begin{tabular}{|c|c|c|c|c|c|c|c|}
\hline \multirow{2}{*}{$\begin{array}{l}\text { Plasma glucose level (mmol/L) } \\
\text { and percentage of glucose level (\%) }\end{array}$} & \multicolumn{7}{|c|}{ Rat group } \\
\hline & Group 1 & Group 2 & Group 3 & Group 4 & Group 5 & Group 6 & Group 7 \\
\hline $\begin{array}{l}\text { Plasma glucose level at week } 0 \\
(\mathrm{mmol} / \mathrm{L})\end{array}$ & $5.21 \pm 2.18$ & $9.52 \pm 4.31$ & $21.61 \pm 5.56$ & $20.41 \pm 5.81$ & $19.75 \pm 5.18$ & $21.55 \pm 4.64$ & $22.26 \pm 6.12$ \\
\hline $\begin{array}{l}\text { Plasma glucose level at week } 4 \\
(\mathrm{mmol} / \mathrm{L})\end{array}$ & $5.34 \pm 3.57$ & $11.69 \pm 5.31$ & $25.47 \pm 4.38^{*}$ & $13.5 \pm 21.13^{* *}$ & $12.70 \pm 15.72^{* *}$ & $13.10 \pm 19.27^{* *}$ & $16.8 \pm 17.22^{* *}$ \\
\hline $\begin{array}{l}\text { Plasma glucose changes from week } \\
0 \text { to week } 4\end{array}$ & 2.4 & 18.6 & 15.2 & -51.6 & -54.3 & -64.5 & -32.4 \\
\hline
\end{tabular}

Data are means \pm SD for plasma glucose level of normal rats (Group 1), obese rats (Group 2), diabetic control rats (Group 3), diabetic rats treated with 50 mg/kg bw of C. latifolia fruit:root extracts (Group 4), diabetic rats treated with $100 \mathrm{mg} / \mathrm{kg}$ bw of C. latifolia fruit:root extracts (Group 5), diabetic rats treated with $200 \mathrm{mg} / \mathrm{kg}$ bw of C. latifolia fruit:root extracts (Group 6), and diabetic rats treated with $10 \mathrm{mg} / \mathrm{kg}$ bw of glibenclamide (Group 7 ) at weeks 0 and 4.

* Are significantly different at $P<0.05$ compared with diabetic control, that is, Group 3 .

** Are significantly different at $P<0.001$ compared with diabetic control, that is, Group 3 .

- Indicates the reduction in plasma glucose.

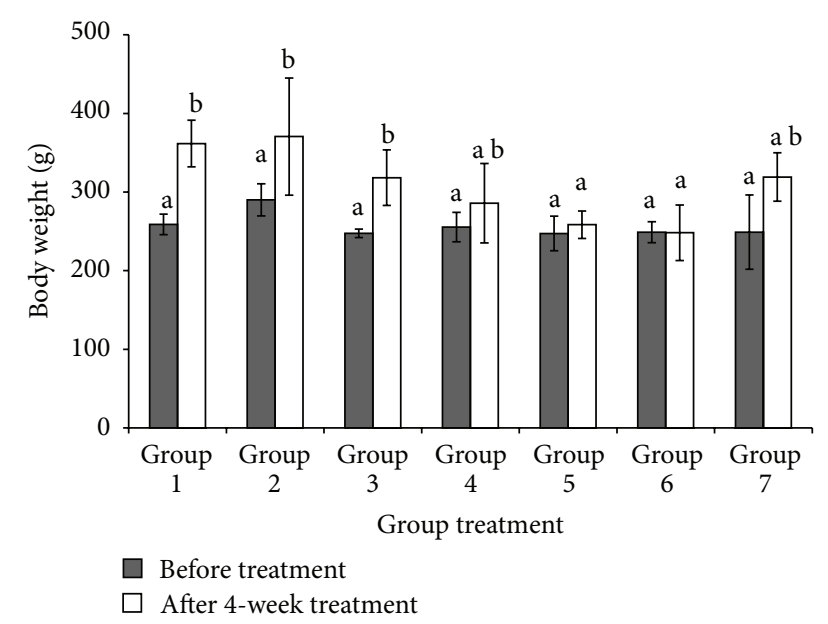

FIGURE 1: Rats body weight before (0 week) and after treatment (4 week). Body weight of normal rats (Group 1), obese rats (Group 2 ), diabetic control rats (Group 3), diabetic rats treated with $50 \mathrm{mg} / \mathrm{kg}$ bw of C. latifolia fruit:root (Group 4), diabetic rats treated with $100 \mathrm{mg} / \mathrm{kg}$ bw of $C$. latifolia fruit:root (Group 5), diabetic rats treated with $200 \mathrm{mg} / \mathrm{kg}$ of C. latifolia fruit:root (Group 6), and diabetic rats treated with $10 \mathrm{mg} / \mathrm{kg}$ bw of glibenclamide (Group 7). Columns represent the mean \pm S.D. $(n=6) .{ }^{\mathrm{a}, \mathrm{b}}$ significantly different at $P<0.05$.

group 7 which has been treated with glibenclamide increased by $19 \%$ (Figure 1 ).

3.3. Plasma Glucose Level. After 4 weeks of intervention, glucose level in normal group was maintained in normal range throughout the experiment although it increased slightly by $2.4 \%$. Meanwhile, glucose level in obese (Group 2) and diabetic control (Group 3) rats was significantly $(P<0.05)$ increased by $18.6 \%$ and $15.2 \%$ by the end of the study. However, glucose level was decreased in treated diabetic rats. The most significant $(P<0.05)$ reduction was showed in diabetic rats treated with $200 \mathrm{mg} / \mathrm{kg}$ bw of C. latifolia fruit:root extracts (Group 6) followed by 100 (Group 5) and 50 (Group 4), 64.5\% > 54.3\% > 51.6\%. Meanwhile, diabetic rats treated with $10 \mathrm{mg} / \mathrm{kg}$ bw of glibenclamide show $32.4 \%$ reduction in glucose level (Table 4 ).

3.4. Plasma Lipid Profiles. Lipid profiles in normal rats were in normal range. However, plasma TC, LDL, and TG levels in obese rats (Group 2) were significantly higher $(P<0.05)$ while HDL level was lower than that normal rats (Group 1) after 4 weeks of study (Table 5). Diabetic control rats (Group 3) also showed a similar pattern to obese rats where plasma TC, TG, and LDL levels were increased by $56.2 \%, 52.6 \%$, and $75.4 \%$ compared to normal rats. However, plasma HDL level in diabetic control rats was decreased by $51 \%$. The higher level of lipid in diabetic control rats can be seen in plasma. Plasma lipids in diabetic control rats were higher and plasma colour has turned to opaque colour instead of clear (Figure 2). The posttreatment levels of TC, TG, and LDL of treated groups were significantly decreased compared to pretreatment levels. Diabetic rats in Groups 4, 5, and 6 showed a significant $(P<$ 0.05 ) reduction in plasma TC, TG, and LDL levels compared to diabetic rats treated with glibenclamide. Besides, HDL level also increased after 4 weeks of treatment in diabetic rats in Groups 4, 5, and 6.

Thus, hypocholesterolemia effect has been found the be higher in $200 \mathrm{mg}$ then followed by $100 \mathrm{mg}$ and $50 \mathrm{mg}$ of $C$. latifolia fruit:root extracts. The most striking result emerging from this study is that lipid content in plasma was ameliorated 
TABLE 5: Lipid profiles of rats group.

\begin{tabular}{|c|c|c|c|c|c|c|c|c|}
\hline \multirow{2}{*}{ Group } & \multicolumn{2}{|c|}{ Total cholesterol (mmol/L) } & \multicolumn{2}{|c|}{ TG (mmol/L) } & \multicolumn{2}{|c|}{$\mathrm{LDL}(\mathrm{mmol} / \mathrm{L})$} & \multicolumn{2}{|c|}{$\mathrm{HDL}(\mathrm{mmol} / \mathrm{L})$} \\
\hline & Before & After & Before & After & Before & After & Before & After \\
\hline 1 & $1.73 \pm 0.29$ & $1.62 \pm 0.18$ & $0.48 \pm 0.26$ & $0.57 \pm 0.11$ & $0.54 \pm 0.31$ & $0.57 \pm 0.42$ & $0.57 \pm 0.22$ & $0.53 \pm 0.24$ \\
\hline 2 & $2.65 \pm 0.11$ & $3.38 \pm 0.16^{*}$ & $0.43 \pm 0.13$ & $1.17 \pm 0.36^{*}$ & $0.77 \pm 0.11$ & $0.92 \pm 0.26$ & $0.54 \pm 0.36$ & $0.26 \pm 0.09$ \\
\hline 3 & $2.17 \pm 0.12$ & $2.53 \pm 0.24$ & $0.60 \pm 0.16$ & $0.87 \pm 0.20$ & $0.70 \pm 0.06$ & $1.00 \pm 0.10^{*}$ & $0.52 \pm 0.05$ & $0.26 \pm 0.15$ \\
\hline 4 & $3.43 \pm 0.15^{*}$ & $1.49 \pm 0.22^{*}$ & $0.53 \pm 0.09$ & $0.64 \pm 0.30$ & $1.34 \pm 0.42^{*}$ & $0.85 \pm 0.06$ & $0.40 \pm 0.15$ & $0.75 \pm 0.21^{*}$ \\
\hline 5 & $2.20 \pm 0.23$ & $1.21 \pm 0.16^{*}$ & $0.52 \pm 0.03$ & $0.67 \pm 0.13^{*}$ & $0.66 \pm 0.16$ & $0.59 \pm 0.38^{*}$ & $0.37 \pm 0.29^{*}$ & $0.82 \pm 0.19^{*}$ \\
\hline 6 & $3.24 \pm 0.10^{*}$ & $1.17 \pm 0.28^{*}$ & $0.60 \pm 0.24$ & $0.69 \pm 0.19^{*}$ & $1.07 \pm 0.15^{*}$ & $0.56 \pm 0.13^{*}$ & $0.34 \pm 0.15^{*}$ & $0.69 \pm 0.20^{*}$ \\
\hline 7 & $2.96 \pm 0.14$ & $1.35 \pm 0.16^{*}$ & $0.45 \pm 0.24$ & $0.59 \pm 0.13^{*}$ & $0.68 \pm 0.17$ & $0.76 \pm 0.24$ & $0.38 \pm 0.11^{*}$ & $0.77 \pm 0.27^{*}$ \\
\hline
\end{tabular}

Data are means \pm SD for lipid profiles of normal rats (Group 1), obese rats (Group 2), diabetic control rats (Group 3), diabetic rats treated with $50 \mathrm{mg} / \mathrm{kg}$ bw of C. latifolia fruit:root extracts (Group 4), diabetic rats treated with $100 \mathrm{mg} / \mathrm{kg}$ bw of C. latifolia fruit:root extracts (Group 5), diabetic rats treated with $200 \mathrm{mg} / \mathrm{kg}$ bw of C. latifolia fruit:root extracts (Group 6), and diabetic rats treated with $10 \mathrm{mg} / \mathrm{kg}$ bw of glibenclamide (Group 7 ) at weeks 0 (before) and 4 (after).

*Are significantly different at $P<0.05$ compared with diabetic control, that is, Group 3.

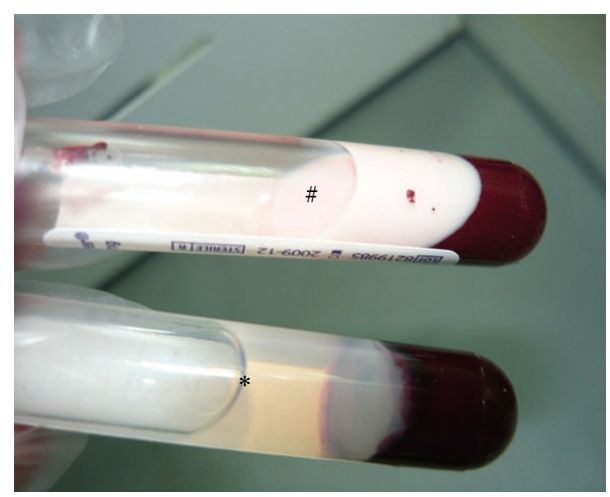

FIGURE 2: Picture of plasma lipid in diabetic control and normal rats. Diabetic control rats are marked with (\#) and normal rats with $(*)$.

when treated with $C$. latifolia extracts. As consequence, the opaque colour in plasma turned into clear in plasma sample in Groups 4, 5, and 6.

3.5. Plasma Insulin and Adiponectin. The changes in insulin level after 4 -week intervention are shown in Figure 3. There was no significant $(P<0.05)$ change in plasma insulin level in normal and diabetic control rats before and after 4 weeks of study. However, plasma insulin level in obese rats significantly increased. Four weeks of treatment with $C$. latifolia fruit:root extract and glibenclamide had increased insulin levels in diabetic rats. There was $16 \%$ of insulin increasing in rats in Group 4 followed by $13 \%$ in Group 5, 12\% in Group 6, and $11 \%$ in Group 7.

There are remarkable changes in adiponectin level in obese and diabetic control rats compared to normal rats (Figure 4). Adiponectin level in obese and diabetic control rats was lower than that normal rats. However, C. latifolia fruit:root extract prevents further decrease in adiponectin in diabetic rats. Adiponectin level was significantly $(P<0.05)$ increased in diabetic rats treated by $C$. latifolia fruit:root extract. Group 5 increased adiponectin level by $56 \%$ followed by Group $4(48 \%)$ and Group 6 (41\%). Besides, in Group 7 there is no significant difference in adiponectin level after 4 weeks of intervention.

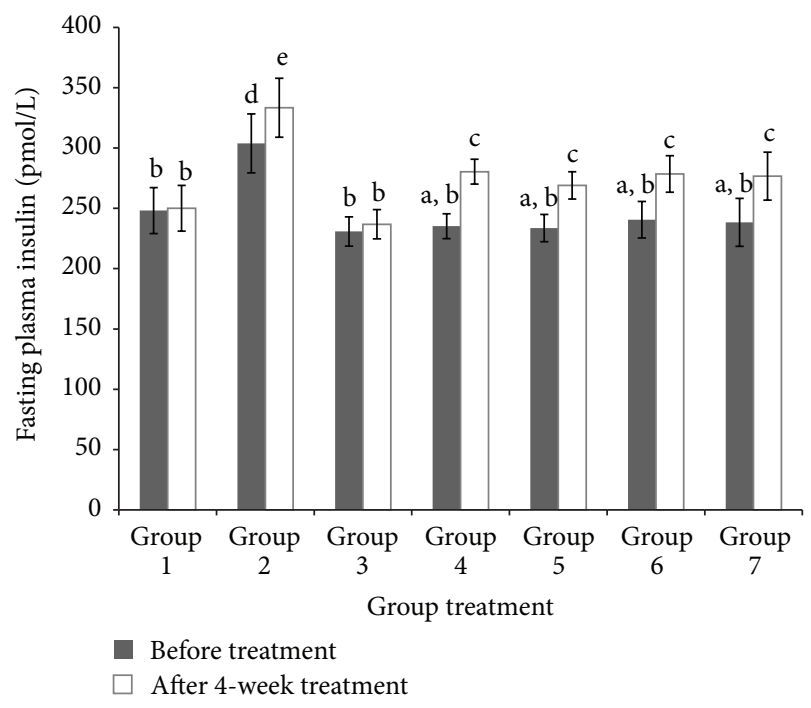

FIGURE 3: Fasting plasma insulin before ( 0 week) and after treatment (4 week). Insulin level of normal rats (Group 1), obese rats (Group 2), diabetic control rats (Group 3), diabetic rats treated with $50 \mathrm{mg} / \mathrm{kg}$ bw of C. latifolia fruit:root (Group 4), diabetic rats treated with $100 \mathrm{mg} / \mathrm{kg}$ bw of C. latifolia fruit:root (Group 5), diabetic rats treated with $200 \mathrm{mg} / \mathrm{kg}$ of C. latifolia fruit:root (Group 6), and diabetic rats treated with $10 \mathrm{mg} / \mathrm{kg}$ bw of glibenclamide (Group 7). Columns represent the mean $\pm \mathrm{SD}(n=6)$. ${ }^{\mathrm{a}, \mathrm{b}, \mathrm{c}}$ significantly different at $P<0.05$.

3.6. Plasma ALT, GGT, Urea, and Creatinine. Results in Table 6 indicate that ALT, GGT, urea, and creatinine levels significantly $(P<0.05)$ increased in obese and diabetic control rats when compared to normal rats. However, there is no significant difference $(P<0.05)$ in ALT, GGT, urea, and creatinine level in diabetic control (Group 3) rats when compared to obese rats. Four weeks of intervention with $C$. latifolia fruit:root extract have reduced ALT, GGT, urea, and creatinine levels towards normalcy in diabetic rats.

3.7. Gene Expression Study Using GeXP Analyzer. Current study was conducted to determine the mechanism of C. latifolia fruit:root extract in alleviating insulin resistance 
TABLE 6: Effect of C. latifolia extracts on ALT, GGT, urea, and creatinine levels in HFD and low dose STZ induced diabetic rats.

\begin{tabular}{|c|c|c|c|c|c|c|c|c|}
\hline \multirow{2}{*}{ Group } & \multicolumn{2}{|c|}{$\operatorname{ALT}(\mathrm{U} / \mathrm{L})$} & \multicolumn{2}{|c|}{ GGT (U/L) } & \multicolumn{2}{|c|}{ Urea $(\mathrm{mmol} / \mathrm{L})$} & \multicolumn{2}{|c|}{ Creatinine $(\mathrm{mmol} / \mathrm{L})$} \\
\hline & Before & After & Before & After & Before & After & Before & After \\
\hline 1 & $75.12 \pm 2.34$ & $109.24 \pm 3.42$ & $6.73 \pm 1.19$ & $5.04 \pm 0.69$ & $5.51 \pm 0.33$ & $5.89 \pm 0.51$ & $31.30 \pm 1.11$ & $30.97 \pm 2.52$ \\
\hline 2 & $88.24 \pm 1.55$ & $114.81 \pm 5.10$ & $8.65 \pm 2.12$ & $10.32 \pm 0.52^{*}$ & $5.07 \pm 0.14$ & $5.82 \pm 0.37$ & $49.40 \pm 2.54$ & $62.90 \pm 3.46^{*}$ \\
\hline 3 & $89.12 \pm 3.42$ & $149.65 \pm 4.26^{*}$ & $13.11 \pm 1.31^{*}$ & $27.88 \pm 2.37^{*}$ & $4.53 \pm 0.35$ & $6.83 \pm 0.40$ & $52.85 \pm 2.68$ & $72.10 \pm 2.58^{*}$ \\
\hline 4 & $77.50 \pm 2.27$ & $76.49 \pm 1.33^{*}$ & $9.53 \pm 1.34$ & $5.39 \pm 0.89^{*}$ & $9.61 \pm 0.16^{*}$ & $6.66 \pm 0.25$ & $58.80 \pm 2.34$ & $47.80 \pm 1.19$ \\
\hline 5 & $76.21 \pm 3.17$ & $84.77 \pm 2.50^{*}$ & $9.07 \pm 1.28$ & $3.18 \pm 1.41$ & $12.55 \pm 0.42$ & $5.66 \pm 0.26^{*}$ & $59.13 \pm 1.19$ & $51.40 \pm 0.77$ \\
\hline 6 & $80.50 \pm 1.24$ & $78.10 \pm 2.46^{*}$ & $9.25 \pm 1.31$ & $5.10 \pm 0.17^{*}$ & $9.15 \pm 0.36$ & $6.65 \pm 0.41$ & $51.93 \pm 0.76$ & $42.60 \pm 0.15$ \\
\hline 7 & $85.74 \pm 5.31$ & $83.10 \pm 3.26^{*}$ & $8.90 \pm 1.19$ & $5.84 \pm 0.21^{*}$ & $14.62 \pm 0.54^{*}$ & $4.98 \pm 0.33$ & $57.63 \pm 0.50$ & $56.21 \pm 0.32$ \\
\hline
\end{tabular}

Data are means \pm SD for ALT, GGT, urea and creatinine levels of normal rats (Group 1), obese rats (Group 2), diabetic control rats (Group 3), diabetic rats treated with $50 \mathrm{mg} / \mathrm{kg}$ bw of C. latifolia fruit:root extracts (Group 4), diabetic rats treated with $100 \mathrm{mg} / \mathrm{kg}$ bw of C. latifolia fruit:root extracts (Group 5), diabetic rats treated with $200 \mathrm{mg} / \mathrm{kg}$ bw of C. latifolia fruit:root extracts (Group 6), and diabetic rats treated with $10 \mathrm{mg} / \mathrm{kg}$ bw of glibenclamide (Group 7). Significant difference is at ${ }^{*} P<0.05$ when compared with diabetic control rats (Group 3).

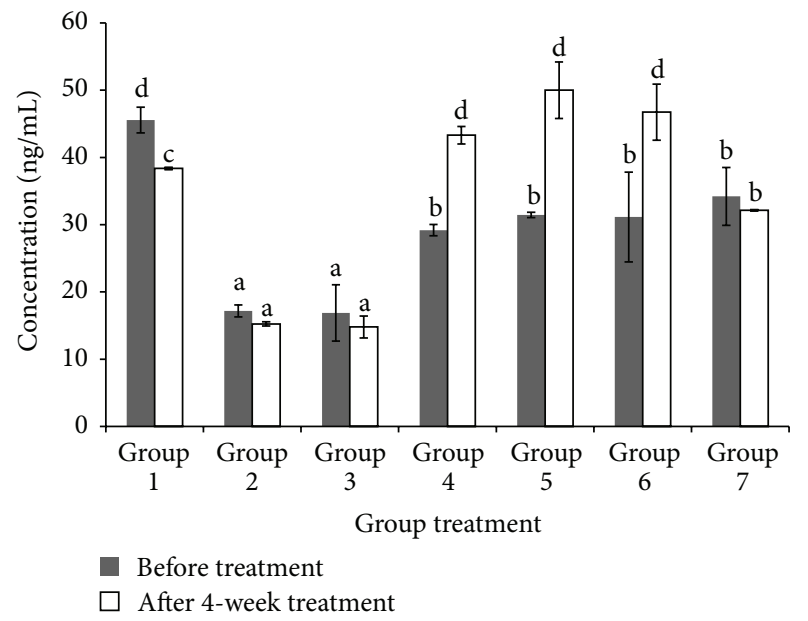

FIGURE 4: Fasting plasma adiponectin before (0 week) and after treatment (4 week). Adiponectin level of normal rats (Group 1), obese rats (Group 2), diabetic control rats (Group 3), diabetic rats treated with $50 \mathrm{mg} / \mathrm{kg}$ bw of C. latifolia fruit:root (Group 4), diabetic rats treated with $100 \mathrm{mg} / \mathrm{kg}$ bw of C. latifolia fruit:root (Group 5), diabetic rats treated with $200 \mathrm{mg} / \mathrm{kg}$ of C. latifolia fruit:root (Group 6), and diabetic rats treated with $10 \mathrm{mg} / \mathrm{kg}$ bw of glibenclamide (Group 7). Columns represent the mean \pm SD. $(n=$ 6). ${ }^{\text {a,b,c }}$ significantly different at $P<0.05$.

through altering expression of genes involved in glucose and lipid metabolisms. In muscle tissue, the expression of IRS1, IGF, GLUT4, PPAR $\alpha$, PPAR $\gamma$, AdipoR1, AdipoR2, leptin, $L P L$, and lipase genes in obese and diabetic control rats was significantly $(P<0.05)$ lower than that in normal rats either in muscle or adipose tissues. However, C. latifolia fruit:root extract significantly $(P<0.05)$ increased the mRNA expression of these genes in diabetic rats as compared to diabetic control rats in Group 3 (Tables 7 and 8).

\section{Discussion}

In order to find the similarity in the development of diabetes in humans, induction of HFD with low dose STZ is the preferred method. However, the rats with HFD will increase their energy expenditure and then lead towards the progression of insulin resistant in the organs. Moreover, low dose STZ induced hyperglycemia in rats where it defects the secretion of insulin [5]. This progressive development of type $2 \mathrm{DM}$ is similar to humans where several researchers agree [36]. In this study, high fat diet was formulated according to Levin et al. (1989) and this diet contains 34\% of fat out of $100 \mathrm{~g}$ of total HFD diet [34]. There was $88 \%$ increase in fat compared to normal diet. Study done by Warwick et al. (2002) has reported that the amount of fat needed in high fat diet must be in the range $30 \%$ to $60 \%$ out of total diet and that is because this amount allows the changes of body weight composition, endocrine secretion and metabolic [37]. Thus, this indicates that, the findings of our HFD are in agreement's with Warwick et al. findings. The current result clearly demonstrated that body weight of obese rats (Group 2) increased over normal rats and this is due to high fat intake. Meanwhile, body weights among diabetic control rats were lower compared to obese rats due to STZ injection. Chatterjee and Shinde (2002) mentioned in their report that STZ causes reduction in body weight due to the loss of tissue protein and increased muscle wasting [38-40]. However, C. latifolia fruit:root extract caused weight loss in diabetic rats in Groups 4, 5, and 6 compared to diabetic control rats. This could be due to lipid lowering activity by C. latifolia fruit:root extract [41]. Besides, body weight among diabetic rats treated with glibenclamide increased compared to diabetic control rats and this indicates that C. latifolia fruit:root extract is better than glibenclamide in order to prevent body weight gain in diabetic models.

Diabetic rats induced by high fat diet with combination of low dose STZ have closely mimicked the natural process of the diabetic occurrence and metabolic disturbance in human diagnosis as type 2 diabetes [42]. In the present study, diabetic model that has been developed using high fat diet with combination of $40 \mathrm{mg}$ of STZ also shows the same symptoms as reported by Unger et al. (2010) [13]. Blood glucose level in diabetic rats was increased and this finding supported the findings of Poitout and Robertson (2002), where they have mentioned that STZ causes destruction of pancreatic $\beta$-cells and it makes the cells less active to be sensitive enough towards insulin for glucose uptake and 
TABLE 7: Expression of candidate genes in muscle tissue.

\begin{tabular}{lccccccccccc}
\hline Group & IRS1 & IGF & GLUT4 & PPAR $\gamma$ & PPAR $\alpha$ & AdipoR1 & AdipoR2 & Leptin & LPL & Lipase & Gapdh \\
\hline Group 1 & 1.8260 & 1.9954 & 0.9704 & 1.5499 & 1.3345 & 1.4130 & 1.2861 & 1.3915 & 0.5263 & 0.5804 & 0.7407 \\
Group 2 & 0.8634 & 0.9465 & 0.5567 & 0.4557 & 0.7075 & 0.5208 & 0.4300 & $2.5701^{*}$ & 0.9524 & 0.9544 & 0.9787 \\
Group 3 & 0.5530 & $0.6140^{*}$ & 0.5163 & 0.3232 & 0.5192 & 0.4040 & 0.3334 & $0.6173^{*}$ & 0.7185 & 0.7652 & 1.0191 \\
Group 4 & $1.3284^{*}$ & $5.2166^{*}$ & $1.3854^{*}$ & $2.0186^{*}$ & $3.0955^{*}$ & $1.4058^{*}$ & $1.5691^{*}$ & $2.1324^{*}$ & 0.8530 & $1.9529^{*}$ & 1.1178 \\
Group 5 & $1.4668^{*}$ & $5.3301^{*}$ & $1.9030^{*}$ & $2.4303^{*}$ & $3.2608^{*}$ & $1.4815^{*}$ & $1.5556^{*}$ & $2.2548^{*}$ & 0.7183 & $1.6386^{*}$ & $1.2593^{*}$ \\
Group 6 & $1.7949^{*}$ & $5.6444^{*}$ & $2.8137^{*}$ & $3.5724^{*}$ & $3.8732^{*}$ & $2.5713^{*}$ & $2.8885^{*}$ & $3.2222^{*}$ & 0.5769 & $2.0382^{*}$ & $1.3244^{*}$ \\
Group 7 & $1.2346^{*}$ & $4.0180^{*}$ & $1.0819^{*}$ & 0.3098 & 0.2155 & 0.8305 & $1.3058^{*}$ & 0.3030 & $1.1089^{*}$ & 0.9428 & $1.2346^{*}$ \\
\hline
\end{tabular}

Data are means \pm SD for expression of candidate genes in muscle tissue of normal rats (Group 1), obese rats (Group 2), diabetic control rats (Group 3), diabetic rats treated with $50 \mathrm{mg} / \mathrm{kg}$ bw of C. latifolia fruit:root extracts (Group 4), diabetic rats treated with $100 \mathrm{mg} / \mathrm{kg}$ bw of C. latifolia fruit:root extracts (Group 5), diabetic rats treated with $200 \mathrm{mg} / \mathrm{kg}$ bw of C. latifolia fruit:root extracts (Group 6), and diabetic rats treated with $10 \mathrm{mg} / \mathrm{kg}$ bw of glibenclamide (Group 7). Significant difference is at ${ }^{*} P<0.05$ when compared with diabetic control rats (Group 3).

TABLE 8: Expression of candidate genes in adipose tissue.

\begin{tabular}{lccccccccccc}
\hline Group & IRS1 & IGF & GLUT4 & PPAR $\gamma$ & PPAR $\alpha$ & AdipoR1 & AdipoR2 & Leptin & LPL & Lipase & Gapdh \\
\hline Group 1 & 1.5371 & 1.8971 & 1.4174 & 1.5781 & 1.7697 & 1.6875 & 1.2268 & 0.9548 & 0.5681 & 0.6158 & 0.9851 \\
Group 2 & 0.4879 & 0.7495 & 0.5275 & 0.2414 & 0.4568 & 0.5967 & 0.5692 & $3.7523^{*}$ & 0.8751 & 0.7681 & 0.8562 \\
Group 3 & 0.4378 & 0.5644 & 0.3194 & 0.2089 & 0.3699 & 0.4298 & 0.4692 & 0.5689 & 0.7521 & 0.5821 & 1.5240 \\
Group 4 & $1.3280^{*}$ & $1.7462^{*}$ & $2.0911^{*}$ & $2.9885^{*}$ & $1.5538^{*}$ & $2.8792^{*}$ & $2.1732^{*}$ & $1.5982^{*}$ & $3.5418^{*}$ & $1.5556^{*}$ & 1.4338 \\
Group 5 & $1.7888^{*}$ & $2.3779^{*}$ & $1.4028^{*}$ & $1.3769^{*}$ & $0.8992^{*}$ & $2.0781^{*}$ & $2.3976^{*}$ & $2.8826^{*}$ & $2.4351^{*}$ & $1.9261^{*}$ & 1.3561 \\
Group 6 & $1.6971^{*}$ & $2.5811^{*}$ & $1.0247^{*}$ & $1.5571^{*}$ & $1.6982^{*}$ & $2.1169^{*}$ & $3.4691^{*}$ & $2.9871^{*}$ & $2.9984^{*}$ & $2.4861^{*}$ & 1.5983 \\
Group 7 & $1.1555^{*}$ & 0.7924 & $1.3333^{*}$ & $1.8634^{*}$ & $0.6282^{*}$ & $1.7295^{*}$ & $1.8059^{*}$ & 1.055 & 0.8564 & 0.7539 & 1.2374 \\
\hline
\end{tabular}

Data are means \pm SD for expression of candidate genes in adipose tissue of normal rats (Group 1), obese rats (Group 2), diabetic control rats (Group 3), diabetic rats treated with $50 \mathrm{mg} / \mathrm{kg}$ bw of C. latifolia fruit:root extracts (Group 4), diabetic rats treated with $100 \mathrm{mg} / \mathrm{kg}$ bw of C. latifolia fruit:root extracts (Group 5), diabetic rats treated with $200 \mathrm{mg} / \mathrm{kg}$ bw of C. latifolia fruit:root extracts (Group 6), and diabetic rats treated with $10 \mathrm{mg} / \mathrm{kg}$ bw of glibenclamide (Group 7).

${ }^{*}$ Indicates $P<0.05$ compared with diabetic control rats (Group 3).

this will cause high glucose concentration in blood [43]. Besides, Bansal et al. (2012) Insulin-mediated glucose uptake mentioned that HFD fed with STZ combination causes hyperglycemia in rats [44]. However, aqueous extract of the C. latifolia fruit:root exhibited a hypoglycemic effect and significantly $(P<0.05)$ decreased the glucose level. Extract at $200 \mathrm{mg} / \mathrm{kg}$ bw has showed a higher decrease compared to other concentrations. It has decreased $64.5 \%$ inblood glucose level and followed by $100 \mathrm{mg} / \mathrm{kg}$ bw and $50 \mathrm{mg} / \mathrm{kg} \mathrm{bw}$. The ability of $C$. latifolia fruit:root extract in reducing glucose level was in agreement with previous finding in an in vitro study (patent pending). C. latifolia increased glucose uptake activity in adipocyte and myotube cells at basal and through insulinmediated glucose/STZ is being uptake: glucose/STZ is being translocation. Besides, C. latifolia also possesses sensitize and insulin mimicking actions in order to stimulate glucose uptake activity. In insulin presence, C. latifolia extracts might sensitizing insulin signaling cascade and stimulates translocation of glucose transporter GLUT4 into plasma membrane and then glucose is being uptake into adipose and muscle through phosphatidylinositol 3-kinase (PI3K) pathway [45].

The abnormality in lipid metabolism in type 2 diabetes mellitus has caused hyperlipidemia in diabetic patient. Thus, diabetic rats that have been induced by HFD with combination of low dose STZ also showed similar situation, hyperlipidemia. This finding further support the idea of Lombardo and Chicco (2006) where it is shown that those rats administrated with HFD cause dyslipidemia and other syndromes in diabetices [46]. Besides, defect in insulin secretion due to STZ also causes defect in lipogenic activity. Insulin plays an important role in stimulating lipogenesis in mammals, by low secretions of insulin it implicates of high level of lipid in plasma [47-49]. Furthermore, plasma colour has turned to opaque due to lipid presence. However, after 4 weeks of treatment with $200 \mathrm{mg} / \mathrm{kg}$ bw of C. latifolia fruit:root extracts, TC, TG, and LDL levels were significantly $(P<$ 0.05 ) decreased and HDL level was increased compared to pretreatment levels. In spite of that, opaque colour in plasma was turned into clear in plasma sample in Groups 4, 5, and 6.

Disruption of pancreatic $\beta$-cells by STZ in diabetic rats has caused insufficient insulin secretion in blood [42]. Thus, this STZ is being uptake into pancreatic cells by GLUT2 and it causes DNA damage via reactive oxygen species generation [42]. However, C. latifolia fruit:root extracts in all concentration have prevented further disruption of cells. It indicates that antioxidant properties of $C$. latifolia have scavenged free radicals which cause oxidative stress in cells. Moreover, adiponectin secretion was also decreased in diabetic control rats. This finding is in agreement with Yang et al's (2006) finding which showed that rats treated with HFD for 4 weeks showed significantly decreased in adiponectin [50]. However, after 4 weeks of treatment with C. latifolia fruit:root extracts, adiponectin levels were increased. The possible mechanism of C. latifolia towards this increasing is due to 
improvement of insulin secretion [41]. Besides, C. latifolia extracts also possess insulin mimicking properties which trigger the adiponectin secretion in adipose tissues. These results suggest that amelioration of insulin and adiponectin secretions by $C$. latifolia fruit:root extract may be a key to decrease glucose and lipid levels in diabetic rats.

Hepatotoxicity and nephropathy are complications from T2DM. Hepatocytes damaged due to hepatotoxicity cause ALT and GGT enzymes leaking out into the blood circulation. Present findings showed that those enzymes were significantly higher in diabetic rats in Groups 2 and 3. These findings are consistent with those of Bolkent et al. (2004) who found that high cholesterol level could cause damage to the liver [51]. Since in our study diabetic rats also showed high cholesterol level, so it supports the idea that high cholesterol level leads to liver damage. Meanwhile, result also shown that creatinine and urea levels were significantly high $(P<0.05)$ in diabetic rats. This finding is similar to that of Sugano et al. (2006) where they had developed nephropathy in T2DM rats model using the same method as in our study and it indicates that HFD and low dose STZ can produce naturally nephropathy symptom similar in humans [52]. However, ALT, GGT, creatinine, and urea levels in diabetic rats treated with C. latifolia fruit:root extract were lower than diabetic control rats. This finding showed that no lethality or toxicity was observed during 4 weeks of intervention with C. latifolia fruit:root extracts on diabetic rats. Besides, it indicates that C. latifolia fruit:root extract prevents further defect in kidney and liver functions.

High fat diet influences human health status by changing cellular function during transcription process [53]. According to Rakhshandehroo et al. (2010), high fat diet may downregulate several transcription factors such as nuclear receptor (PPAR) and sterol regulatory binding proteins (GLUT) [53]. IRS-1, GLUT4, and IGF-1 are responsible of glucose metabolisms. Binding of insulin on IRS initiates PI3K substrates and triggers the activation of glucose transporter (GLUT4) vesicles to plasma membrane for glucose uptake [54]. Meanwhile, IGF-1 also has direct effect in order to trigger insulin sensitivity and regulate glucose uptake similar to insulin. Although insulin and IGF has similar mechanism in inducing glucose uptake, several studies showed that IGF is more efficient than insulin [55]. Thus, our finding showed that IRS-1, IGF-1, and GLUT4 genes have been downregulated in obese and diabetic control rats. This finding was associated with the occurrence of defect insulin secretion and insulin resistance in obese and diabetic control rats [56]. However, C. latifolia fruit:root extract increased IRS-1, IGF-1, and GLUT4 genes expression in diabetic rats. The augmented expression of these genes is due to the ability of $C$. latifolia fruit:root extract to increase insulin secretion and sufficient insulin will trigger the expression of IRS-1 gene. Moreover, expression of IGF-1 gene was higher compared to IRS-1. This indicates that $C$. latifolia fruit:root extract is more potent to improve glucose metabolism through IGF-1 action than IRS1. Besides, it also indicates that C. latifolia fruit: root extract could act in two different situations, early and late phase of type 2 diabetes where pancreatic cells could not keep up with demand. However, further study needs to be done to study the mechanism involved.

Meanwhile, PPAR $\gamma$ and PPAR $\alpha$ were also downregulated in obese and diabetic control rats. Research done by Petersson et al. (2009) has also found that the occurrence of insulin resistance, hyperglycemia, and dyslipidemia in diabetes subjects is because of downregulation of several genes such as IGF-1, PPAR, and GLUT families [57, 58]. Four weeks of intervention with $C$. latifolia fruit:root extract caused upregulation of PPAR $\gamma$ gene. According to Pita et al. (2012), the upregulation of $P P A R \gamma$ will stimulate IRS-1, IGF-1, GLUT4, AdipoR1, AdipoR2, LPL, PPAR , leptin, and lipase genes expression in the treated diabetic rats [59] and their findings support our results where the same genes are also being upregulated. Besides, C. latifolia fruit:root extract might have similar action to thiazolidinedione (TZD) which possess PPAR $\gamma$ ligand-binding activity and stimulate PPAR $\gamma$ transcription [60].

On the other hand, AdipoR1, AdipoR2, leptin, LPL, and lipase genes were also downregulated in diabetic control rats either in muscle and adipose tissues. According to Kadowaki and Yamauchi (2005), AdipoR1 and AdipoR2 ameliorate defect in glucose and lipid metabolism through different pathways [61]. AdipoR1 activates the AMPK pathway in order to reduce hepatic glucose production and increase FA oxidation. Meanwhile, AdipoR2 activates PPAR $\alpha$ pathway [61]. In the present study, C. latifolia fruit:root extract increased regulation of AdipoR1 and AdipoR2 genes. These genes might be upregulated during adipocyte differentiation or through other genes expression. According to Pita et al. (2012), the enhancement of adiponectin receptors expression is correlated with increasing AMPK activity which is necessary for adiponectin action [59]. Our finding is parallel to their finding where $C$. latifolia fruit:root extract augmented glucose metabolism genes such as IRS-1, IGF-1, and GLUT4 and it might increase AMPK activity in diabetic rats and lead to upregulation of AdipoR1 and AdipoR2 genes.

Several studies have indicated the importance of PPAR $\alpha$ in lipid and glucose metabolisms [62]. According to Gross and Staels (2007), activation of PPAR $\alpha$ may express other genes involved in lipid and lipoprotein metabolism [62]. Besides, PPAR $\alpha$ is also responsible of glucose homeostasis and it directly regulates gluconeogenesis due to pyruvate dehydrogenase kinase 4 expression [63]. Apart from that, PPAR $\alpha$ has the ability to prevent insulin resistance in diabetic due to the increase of fatty acids oxidation in pancreas, muscle and liver [64]. In spite of that, it also improves insulin secretion by preventing lipotoxicity and glucotoxicity in pancreatic cells [65]. In the present study, C. latifolia fruit:root extracts upregulate PPAR $\alpha$ transcription in both muscle and adipose tissues of diabetic rats. The activation of PPAR $\alpha$ will lead to high level of HDL and low level of TG in diabetic model [53]. This finding is in agreement with the present data where TG level was decreased and HDL level was increased in treated diabetic rats after 4 weeks of intervention with C. latifolia fruit:root extracts. Moreover, the upregulation of PPAR $\alpha$ will initiate the regulation of genes involved in lipoprotein metabolism such as LPL [52]. Thus, it compliments with the recent study where C. latifolia 
fruit:root extracts increased LPL expression in diabetic rats. The possible mechanism that can be drawn from this finding is that C. latifolia fruit:root extract indirectly increased LPL expression via activation of PPAR $\alpha$ through adipocytokine signaling pathway. Apart from that, LPL expression might be another possible explanation on how opaque colour in plasma turned into clear. Lipid content in plasma will be hydrolyzed by LPL and converted into TG for storage [66]. Besides, slight increase in body weight among treated diabetic rats was due to upregulation of leptin expression.

\section{Conclusion}

The present study demonstrates that C. latifolia fruit:root extract reduced glucose and lipid levels in diabetic rats. Meanwhile, insulin and adiponectinlevels were increased. The extract exerts antidiabetic and hypolipidemic effects by stimulating PPAR $\gamma$, IRS-1, IGF-1, GLUT4, AdipoR1, AdipoR2, LPL, PPAR $\alpha$, leptin, and lipase expressions in adipose and muscle tissues. The antidiabetic and hypolipidemic activities of C. latifolia fruit:root support its potential as a therapeutic option for diabetes and its complication.

\section{Conflict of Interests}

The authors declare that they have no conflict of interests.

\section{Acknowledgment}

This work was supported by the fundamental research grant scheme (FRGS) from the Ministry of Higher Education, Malaysia.

\section{References}

[1] H. Pareek, S. Sharma, B. S. Khajja, K. Jain, and G. C. Jain, "Evaluation of hypoglycemic and anti-hyperglycemic potential of Tridax procumbens (Linn.)," BMC Complementary and Alternative Medicine, vol. 9, article 48, 2009.

[2] X. K. Zheng, Y. J. Li, L. Zhang, W. S. Feng, and X. Zhang, "Antihyperglycemic activity of Selaginella tamariscina (Beauv.) Spring," Journal of Ethnopharmacology, vol. 133, no. 2, pp. 531537, 2011.

[3] H. E. Lebovitz and M. A. Banerji, "Treatment of insulin resistance in diabetes mellitus," European Journal of Pharmacology, vol. 490, no. 1-3, pp. 135-146, 2004.

[4] Y. Wang, J. Yu, C. Zhang et al., "Influence of flavonoids from Phellinus igniarius on sturgeon caviar: antioxidant effects and sensory characteristics," Food Chemistry, vol. 131, no. 2, pp. 206210, 2012.

[5] D. K. Patel, R. Kumar, D. Laloo, and S. Hemalatha, "Diabetes mellitus: an overview on its pharmacological aspects and reported medicinal plants having antidiabetic activity," Asian Pacific Journal of Tropical Biomedcine, vol. 4, no. 3, pp. 411-420, 2012.

[6] K. Srinivasan, B. Viswanad, L. Asrat, C. L. Kaul, and P. Ramarao, "Combination of high-fat diet-fed and low-dose streptozotocintreated rat: a model for type 2 diabetes and pharmacological screening," Pharmacological Research, vol. 52, no. 4, pp. 313-320, 2005.
[7] D. S. Prasad, Z. Kabir, A. K. Dash, and B. C. Das, "Abdominal obesity, an independent cardiovascular risk factor in Indian subcontinent: a clinico epidemiological evidence summary," Journal of Cardiovascular Disease Research, vol. 32, no. 2, pp. 199-205, 2011.

[8] X. Zheng, L. Zhang, W. Wang, Y. Wu, Q. Zhang, and W. Feng, "Anti-diabetic activity and potential mechanism of total flavonoids of Selaginella tamariscina (Beauv.) Spring in rats induced by high fat diet and low dose STZ," Journal of Ethnopharmacology, vol. 137, no. 3, pp. 662-668, 2012.

[9] S. M. Clee and A. D. Attie, "The genetic landscape of type-2 diabetes in mice," Endocrinology Reviews, vol. 28, no. 2, pp. 4883, 2006.

[10] P. Masiello, "Animal models of type-2 diabetes with reduced pancreatic $\beta$-cell mass," The International Journal of Biochemistry and Cell Biology, vol. 38, no. 9, pp. 873-893, 2006.

[11] M. D. Mythili, R. Vyas, G. Akila, and S. Gunasekaran, "Effect of Streptozotocin on the ultrastructure of rat pancreatic islets," Microscopy Research and Technique, vol. 63, no. 5, pp. 274-281, 2004.

[12] E. Shafrir, "Diabetes in animals: contribution to the understanding of diabetes by study of its etiophatology in animal models," in Diabetes Mellitus, D. Porte, R. S. Sherwin, and A. Baron, Eds., pp. 231-255, McGraw-Hill, New York, NY, USA, 2003.

[13] R. H. Unger, G. O. Clark, P. E. Scherer, and L. Orci, "Lipid homeostasis, lipotoxicity and the metabolic syndrome," Biochimica et Biophysica Acta, vol. 1801, no. 3, pp. 209-214, 2010.

[14] Y. Zhang, X. Li, D. Zou et al., "Treatment of type 2 diabetes and dyslipidemia with the natural plant alkaloid berberine," Journal of Clinical Endocrinology and Metabolism, vol. 93, no. 7, pp. 2559-2565, 2008.

[15] F. Franconi, G. Seghieri, S. Canu, E. Straface, I. Campesi, and W. Malorni, "Are the available experimental models of type 2 diabetes appropriate for a gender perspective?" Pharmacological Research, vol. 57, no. 1, pp. 6-18, 2008.

[16] K. Sahin, M. Onderci, M. Tuzcu et al., "Effect of chromium on carbohydrate and lipid metabolism in a rat model of type 2 diabetes mellitus: the fat-fed, streptozotocin-treated rat," Metabolism, vol. 56, no. 9, pp. 1233-1240, 2007.

[17] S. Zhao, Y. Chu, C. Zhang et al., "Diet-induced central obesity and insulin resistance in rabbits," Journal of Animal Physiology and Animal Nutrition, vol. 92, no. 1, pp. 105-111, 2008.

[18] S. Bastaki, "Diabetes mellitus and its treatment," International Journal of Diabetes and Metabolism, vol. 13, no. 3, pp. 111-134, 2005.

[19] J. G. Schier, O. N. Hirsch, J. Chu, S. McLaughlin, P. McKinney, and C. Crandall, "Octreotide as antidote for sulfonylureainduced hypoglycemia," Annals of Emergency Medicine, vol. 37, no. 4, pp. 417-418, 2001.

[20] C. M. Nzerue, J. Thomas, J. Volcy, and T. Edeki, "Use of octreotide to treat prolonged sulfonylurea-induced hypoglycemia in a patient with chronic renal failure," International Journal of Artificial Organs, vol. 26, no. 1, pp. 86-89, 2003.

[21] R. E. Amori, J. Lau, and A. G. Pittas, "Efficacy and safety of incretin therapy in type 2 diabetes: systematic review and metaanalysis," Journal of the American Medical Association, vol. 298, no. 2, pp. 194-206, 2007.

[22] International Diabetes Federation, 2009, https://www.idf.org/ latest-diabetes-figures-paint-grim-global-picture.

[23] H. Lü, J. Chen, W. L. Li et al., "Hypoglycemic and hypolipidemic effects of the total triterpene acid fraction from Folium 
Eriobotryae," Journal of Ethnopharmacology, vol. 122, no. 3, pp. 486-491, 2009.

[24] W. L. Li, H. C. Zheng, J. Bukuru, and N. De Kimpe, "Natural medicines used in the traditional Chinese medical system for therapy of diabetes mellitus," Journal of Ethnopharmacology, vol. 92, no. 1, pp. 1-21, 2004.

[25] A. Ravi Kumar, S. Ponnusamy, R. Ravindran, S. Zinjarde, and S. Bhargava, "Evaluation of traditional Indian antidiabetic medicinal plants for human pancreatic amylase inhibitory effect in vitro," Evidence-Based Complementary and Alternative Medicine, vol. 2011, Article ID 515647, 10 pages, 2011.

[26] N. Malviya, S. Jain, and S. Malviya, "Antidiabetic potential of medicinal plants," Acta Poloniae Pharmaceutica, vol. 67, no. 2, pp. 113-118, 2010.

[27] S. H. Jung, H. J. Seol, S. J. Jeon, K. H. Son, and J. R. Lee, "Insulinsensitizing activities of tanshinones, diterpene compounds of the root of Salvia miltiorrhiza Bunge," Phytomedicine, vol. 16, no. 4, pp. 327-335, 2009.

[28] R. Dheer and P. Bhatnagar, "A study of the antidiabetic activity of Barleria prionitis Linn," Indian Journal of Pharmacology, vol. 42, no. 2, pp. 70-73, 2010.

[29] R. Randhir and K. Shetty, "Mung beans processed by solid-state bioconversion improves phenolic content and functionality relevant for diabetes and ulcer management," Innovative Food Science and Emerging Technologies, vol. 8, no. 2, pp. 197-204, 2007.

[30] I. M. Firdaus, A. Nur Ashikin Psyquay, S. Ghizan, and I. Maznah, "Anthesis and flower visitors in Curculigo latifolia Dryand," Journal of Biology and Life Sciences, vol. 1, no. 1, pp. 13-15, 2010.

[31] O. H. Chooi, Tumbuhan Liar: khasiat Ubatan Dan Kegunaan Lain, Utusan Publications and Distributors Sendirian Berhad, Kuala Lumpur, Malaysia, 2006.

[32] R. Kant, "Sweet proteins-potential replacement for artificial low calorie sweeteners," Nutrition Journal, vol. 4, article 5, 2005.

[33] A. Shimizu-Ibuka, Y. Morita, T. Terada et al., "Crystal structure of neoculin: insights into its sweetness and taste-modifying activity," Journal of Molecular Biology, vol. 359, no. 1, pp. 148158, 2006.

[34] B. E. Levin, S. Hogan, and A. C. Sullivan, "Initiation and perpetuation of obesity and obesity resistance in rats," American Journal of Physiology, vol. 256, no. 3, pp. 766-771, 1989.

[35] M. K. Tuck, D. W. Chan, D. Chia et al., "Standard operating procedures for serum and plasma collection: early detection research network consensus statement standard operating procedure integration working group," Journal of Proteome Research, vol. 8, no. 1, pp. 113-117, 2009.

[36] T. Y. Reuter, "Diet-induced models for obesity and type 2 diabetes," Drug Discovery Today, vol. 4, no. 1, pp. 3-8, 2007.

[37] Z. S. Warwick, S. J. Synowski, and K. R. Bell, "Dietary fat content affects energy intake and weight gain independent of diet caloric density in rats," Physiology and Behavior, vol. 77, no. 1, pp. 85-90, 2002.

[38] M. N. Chatterjee and R. Shinde, Text Book of Medical Biochemistry, Jaypee Brothers, 2002.

[39] N. Kumar and C. S. Dey, "Metformin enhances insulin signalling in insulin-dependent and -independent pathways in insulin resistant muscle cells," British Journal of Pharmacology, vol. 137, no. 3, pp. 329-336, 2002.

[40] B. Rangachari and I. Savarimuthu, "Antidiabetic and Hypolipidemic effect of methanol extract of Lippia nodiflora L. in streptozotocin induced diabetic rats," Asian Pacific Journal of Tropical Biomedicine, vol. 1, no. 1, pp. 30-36, 2011.

[41] H. Jouad, A. Lemhadri, M. Maghrani, N. A. Zeggwagh, and M. Eddouks, "Cholesterol-lowering activity of the aqueous extract of Spergularia purpurea in normal and recent-onset diabetic rats," Journal of Ethnopharmacology, vol. 87, no. 1, pp. 43-49, 2003.

[42] Y. Li, P. Wang, Y. Zhuang et al., "Activation of AMPK by berberine promotes adiponectin multimerization in 3T3-L1 adipocytes," FEBS Letters, vol. 585, no. 12, pp. 1735-1740, 2011.

[43] V. Poitout and R. P. Robertson, "Minireview: secondary $\beta$-cell failure in type 2 diabetes - a convergence of glucotoxicity and lipotoxicity," Endocrinology, vol. 143, no. 2, pp. 339-342, 2002.

[44] P. Bansal, P. Paul, J. Mudgal et al., "Antidiabetic, antihyperlipidemic and antioxidant effects of the flavonoid rich fraction of Pilea microphylla (L.) in high fat diet/streptozotocin-induced diabetes in mice," Experimental and Toxicologic Pathology, vol. 64, pp. 651-658, 2012.

[45] S. Frojdo, C. Durand, L. Molin et al., "Phosphoinositide 3kinase as a novel functional target for the regulation of the insulin signaling pathway by SIRT1," Molecular and Cellular Endocrinology, vol. 335, no. 2, pp. 166-176, 2011.

[46] Y. B. Lombardo and A. G. Chicco, "Effects of dietary polyunsaturated n-3 fatty acids on dyslipidemia and insulin resistance in rodents and humans. A review," Journal of Nutritional Biochemistry, vol. 17, no. 1, pp. 1-13, 2006.

[47] A. S. Rossi, Y. B. Lombardo, and A. G. Chicco, "Lipogenic enzyme activities and glucose uptake in fat tissue of dyslipemic, insulin-resistant rats: effects of fish oil," Nutrition, vol. 26, no. 2, pp. 209-217, 2010.

[48] A. Gomes, J. R. Vedasiromoni, M. Das, R. M. Sharma, and D. K. Ganguly, "Anti-hyperglycemic effect of black tea (Camellia sinensis) in rat," Journal of Ethnopharmacology, vol. 45, no. 3, pp. 223-226, 1995.

[49] A. S. Shingo, T. Kanabayashi, T. Murasea, and S. Kito, "Cognitive decline in STZ-3V rats is largely due to dysfunctional insulin signaling through the dentate gyrus," Behavioural Brain Research, vol. 229, no. 9, pp. 378-383, 2012.

[50] B. Yang, L. Chen, Y. Qian et al., "Changes of skeletal muscle adiponectin content in diet-induced insulin resistant rats," Biochemical and Biophysical Research Communications, vol. 341, no. 1, pp. 209-217, 2006.

[51] S. Bolkent, R. Yanardag, S. Bolkent, and M. M. Döger, "Beneficial effects of combined treatment with niacin and chromium on the liver of hyperlipemic rats," Biological Trace Element Research, vol. 101, no. 3, pp. 219-229, 2004.

[52] M. Sugano, H. Yamato, T. Hayashi et al., "High-fat diet in lowdose-streptozotocin-treated heminephrectomized rats induces all features of human type 2 diabetic nephropathy: a new rat model of diabetic nephropathy," Nutrition, Metabolism and Cardiovascular Diseases, vol. 16, no. 7, pp. 477-484, 2006.

[53] M. Rakhshandehroo, B. Knoch, M. Müller, and S. Kersten, "Peroxisome proliferator-activated receptor alpha target genes," PPAR Research, vol. 2010, Article ID 612089, 20 pages, 2010.

[54] C. J. Rhodes and M. F. White, "Molecular insights into insulin action and secretion," European Journal of Clinical Investigation, vol. 32, no. 3, pp. 3-13, 2002.

[55] J. Palsgaard, A. E. Brown, M. Jensen, R. Borup, M. Walker, and P. De Meyts, "Insulin-like growth factor I (IGF-I) is a more potent regulator of gene expression than insulin in primary human myoblasts and myotubes," Growth Hormone and IGF Research, vol. 19, no. 2, pp. 168-178, 2009. 
[56] S. Teppala and A. Shankar, "Association between serum IGF-1 and diabetes among U.S. adults," Diabetes Care, vol. 33, no. 10, pp. 2257-2259, 2010.

[57] Y. Wang, D. Zhang, Y. Liu et al., "Association study of the single nucleotide polymorphisms in adiponectin-associated genes with type 2 diabetes in Han Chinese," Journal of Genetics and Genomics, vol. 36, no. 7, pp. 417-423, 2009.

[58] U. Petersson, C. J. Östgren, L. Brudin, K. Brismar, and P. M. Nilsson, "Low levels of insulin-like growth-factor-binding protein-1 (IGFBP-1) are prospectively associated with the incidence of type 2 diabetes and impaired glucose tolerance (IGT): The Söderåkra Cardiovascular Risk Factor Study," Diabetes and Metabolism, vol. 35, no. 3, pp. 198-205, 2009.

[59] J. Pita, A. Panadero, L. Soriano-Guillén, E. Rodríguez, and A. Rovira, "The insulin sensitizing effects of PPAR- $\gamma$ agonist are associated to changes in adiponectin index and adiponectin receptors in Zucker fatty rats," Regulatory Peptides, vol. 174, no. 7, pp. 18-25, 2012.

[60] M. Kuroda, Y. Mimaki, S. Honda, H. Tanaka, S. Yokota, and T. Mae, "Phenolics from Glycyrrhiza glabra roots and their PPAR$\gamma$ ligand-binding activity," Bioorganic and Medicinal Chemistry, vol. 18, no. 2, pp. 962-970, 2010.

[61] T. Kadowaki and T. Yamauchi, "Adiponectin and adiponectin receptors," Endocrine Reviews, vol. 26, no. 3, pp. 439-451, 2005.

[62] B. Gross and B. Staels, "PPAR agonists: multimodal drugs for the treatment of type-2 diabetes," Best Practice and Research in Clinical Endocrinology and Metabolism, vol. 21, no. 4, pp. 687710, 2007.

[63] F. Lalloyer, B. Vandewalle, F. Percevault et al., "Peroxisome proliferator-activated receptor $\alpha$ improves pancreatic adaptation to insulin resistance in obese mice and reduces lipotoxicity in human islets," Diabetes, vol. 55, no. 6, pp. 1605-1613, 2006.

[64] B. Staels and J. C. Fruchart, "Therapeutic roles of peroxisome proliferator-activated receptor agonists," Diabetes, vol. 54, no. 8, pp. 2460-2470, 2005.

[65] K. Ravnskjaer, M. Boergesen, B. Rubi et al., "Peroxisome proliferator-activated receptor $\alpha$ (PPAR $\alpha)$ potentiates, whereas PPAR $\gamma$ attenuates, glucose-stimulated insulin secretion in pancreatic $\beta$-cells," Endocrinology, vol. 146, no. 8, pp. 3266-3276, 2005.

[66] G. R. Hajer, T. W. Van Haeften, and F. L. J. Visseren, "Adipose tissue dysfunction in obesity, diabetes, and vascular diseases," European Heart Journal, vol. 29, no. 24, pp. 2959-2971, 2008. 


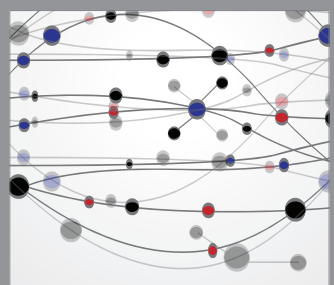

The Scientific World Journal
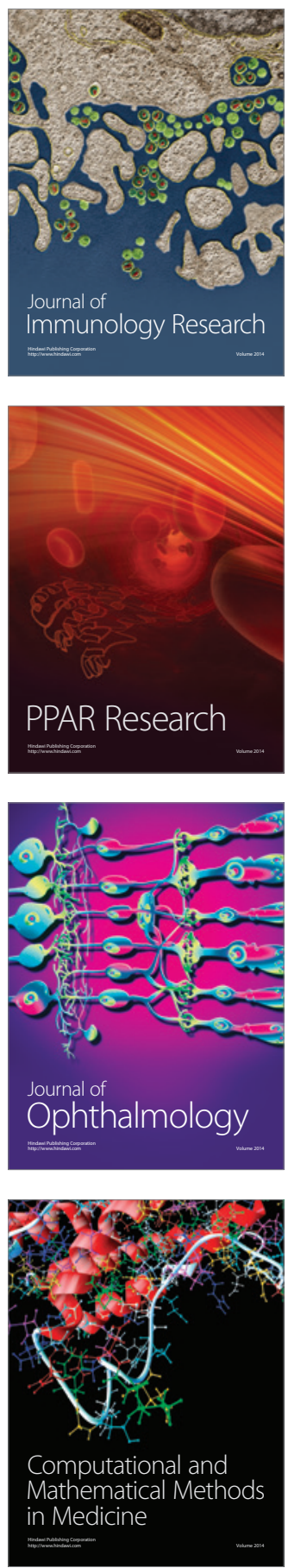

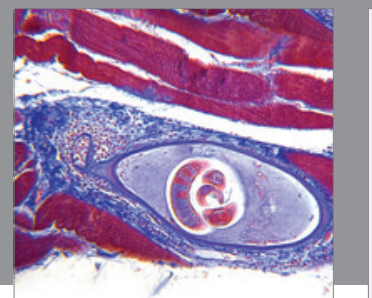

Gastroenterology

Research and Practice
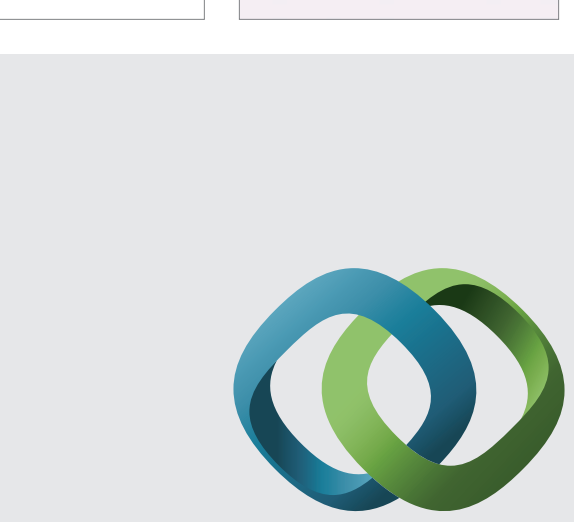

\section{Hindawi}

Submit your manuscripts at

http://www.hindawi.com
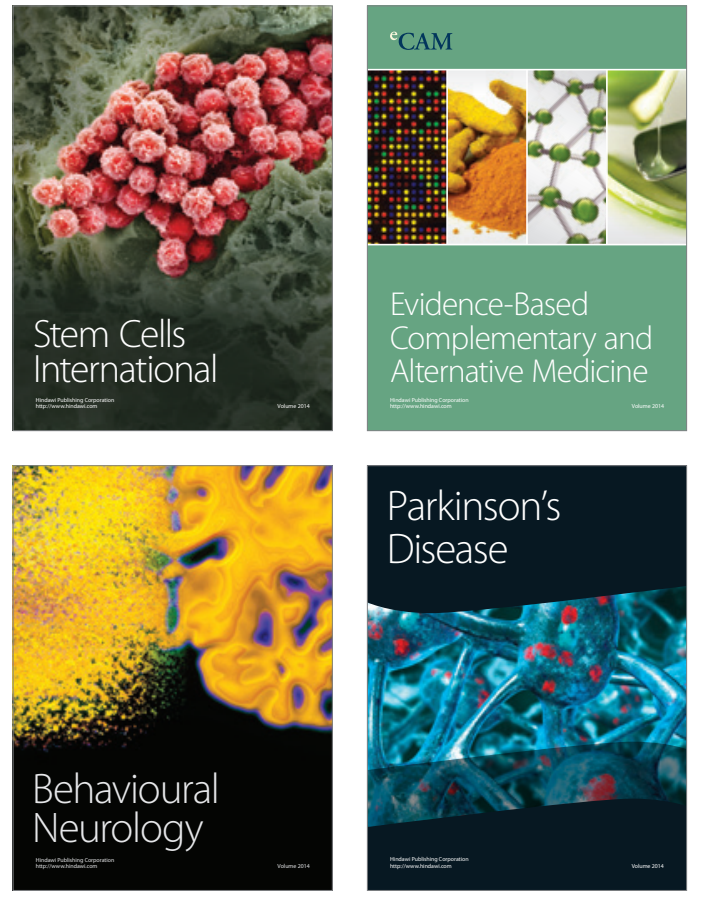
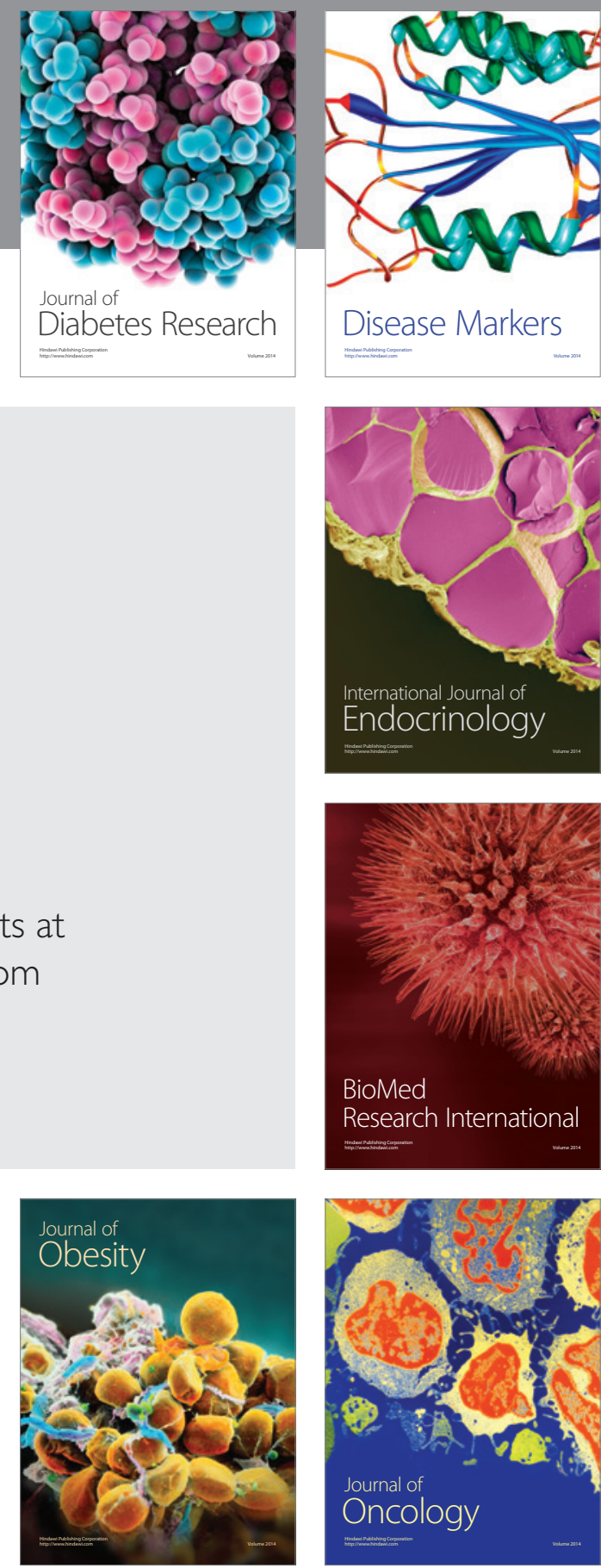

Disease Markers
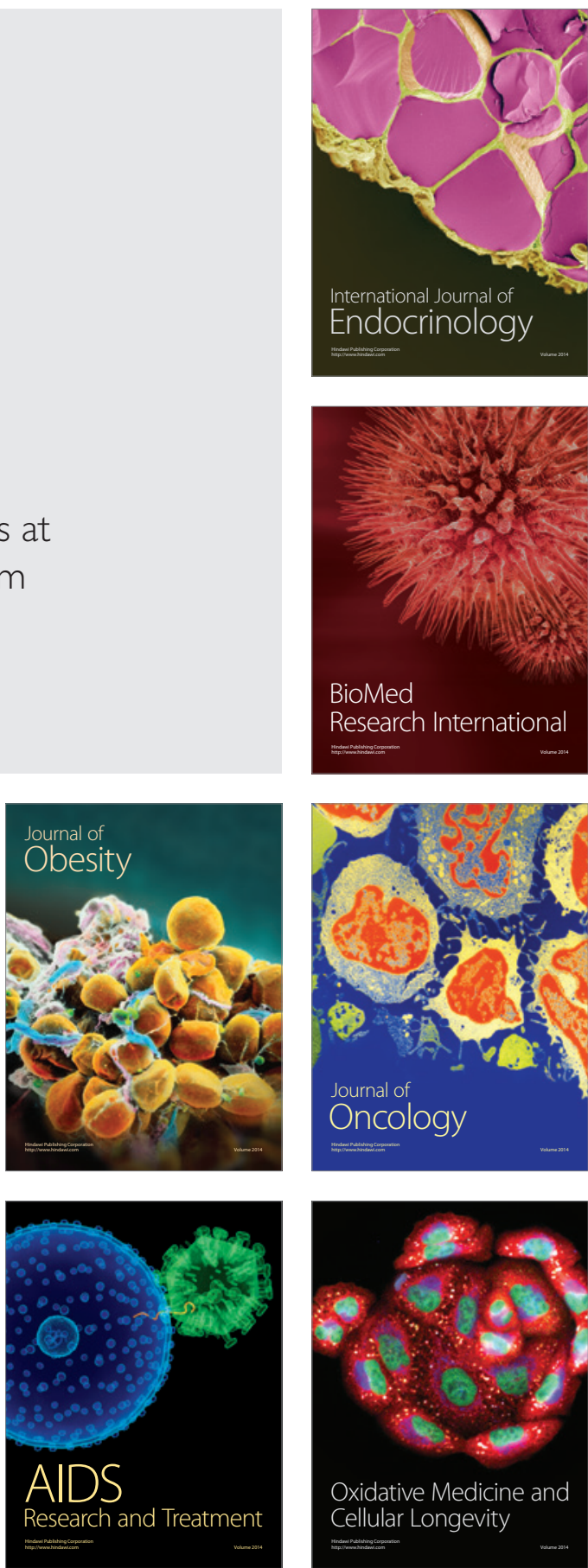